\title{
ECPR CONFERENCE ANNOUNCEMENTS
}

doi:10.1057/eps.2009.11

10-12 SEPTEMBER 2009

5th ECPR General Conference to be held at Potsdam Universität

Over 2,000 participants are expected to attend - our largest event yet!

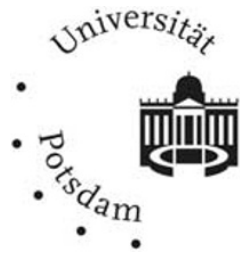

Registration now open.

\section{AUGUST-1 SEPTEMBER 2010}

3rd ECPR Graduate Conference to be held at Dublin City University

Building on the success of the Barcelona Graduate Conference, this one will be bigger and better.

Look out for the call for papers, coming soon to a notice board near you!

25-27 AUGUST 2011 (dates to be confirmed)

6th ECPR General Conference to be held at the University of Iceland

Missing out on Potsdam? Be sure to submit a proposal and

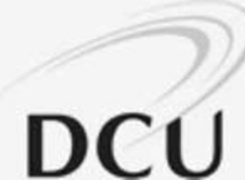
add the date to your diary.

MISS IT, MISS OUT! 